\title{
Zum Nachweis fremder Farbstoffe in Fetten.
}

\author{
Von \\ H. Sprinkmeyer und H. Wagner. \\ Mitteilung aus dem staatlichen Chemischen Untersuchungsamte für die \\ Auslandsfleischbeschan za Goch.
}

In letzter Zeit ist mehrfach der Versuch gemacht worden, zubereitete Fette, besonders Talg, mit einem Zusatz fremder Farbstoffe in das Zollinland einzuführen. Dieser Umstand veranlaßte uns, sowohl die amtlichen Vorschriften als auch einige Literaturangaben über den Nachweis von fremden Farbstoffen in Fetten einer näheren Prüfung zu unterziehen. Wir baben dabei die Erfahrung gemacht, daß einzelne der angegebenen Methoden nicht mit genügender Sicherheit die Gegenwart fremder Farbstoffe erkennen lassen. Dagegen gelingt ein sicherer und schneller Nachweis eines Farbstoffzusatzes in Fetten nach einem von uns ermittelten und unten näher beschriebenen Verfahren.

Sowohl nach den Vorschriften der amtlichen „Anweisung für die chemische Untersuchung von Fleisch und Fetten" Anlage d zu den Bundesratsbestimmungen D vom 30. Mai 1902 zum Reichsgesetz, betreffend die Schlachtvieh- und Fleischbeschau, vom 3. Juni 1900 , als auch nach der ,Anweisung zur chemischen Untersuchung von Fetten und Käsen", Bekanntmachung vom 1. April 1898, soll zum Nachweise fremder Farbstoffe das geschmolzene Fett mit etwa der doppelten Menge absolutem Alkohol ausgeschüttelt werden. Der Farbstoffzusatz soll sich durch deutlich gelbe oder rötlichgelbe Färbung der erkalteten alkoholischen Lösung erkennen lassen.

Zum Nachweis bestimmter Teerfarbstoffe sind $2-3 \mathrm{~g}$ Fett in $5 \mathrm{ccm}$ Äther zu lösen und die Lösung ist in einem Probierröhrchen mit $5 \mathrm{ccm}$ Salzsäure vom spezifischen Gewichte 1,125 kräftig zu schütteln. Bei Gegenwart gewisser Azofarbstoffe ist die sich absetzende Salzeäureschicht deutlich rot gefärbt. Allerdings ist der Nachweis nach letzterem Verfahren recht leicht zu führen. Das Verfahren ist aber eben nur zum Nachweis gewisser Azofarbstoffe brauchbar. Nach der ersten Vorschrift durch Ausschütteln des geschmolzenen Fettes mit der doppelten Menge absoluten Alkohols ist ein Farbstoffzusatz, insbesondere bei Talg, zumal wenn er nur gering ist, oft recht schwer festzustellen. Es ist zu diesem Zwecke vielfach notwendig, den Talg mit absolutem Alkohol längere Zeit am Rückflußkühler auf dem Wasserbade zu erwärmen. Hierbei ist es nicht ausgeschlossen, daß geringe Mengen Talg bezw. Talgöl in Lösung: gehen, die für sich schon den Alkohol färben können, sodaß dieses Verfahren keinen sicheren Anhaltspunkt für einen stattgehabten Farbstoffzusatz gibt. Weiterhin gaben Fette, die wir selbst mit sehr geringen Mengen Farbstoff versetzten, nach den amtlich vorgeschriebenen Verfahr en keine oder nur recht schwache Färbungen des Alkohols.

Moore ${ }^{1}$ ) und Martin ${ }^{2}$ ) wenden zum Nachweise fremder Farbstoffe Alkohol (Methyl- oder Äthylalkohol) und Schwefelkohlenstoff an. Der Alkohol soll den Farbstoff aufnehmen, während der Schwefelkohlenstoff das Fett gelöst enthalten soll. Bei mehreren, von uns selbst gefärbten Fetten versagte jedoch diese Methode, da der

1) Analyst 1886, 11, 168 .

2) Analyst 1887, 12, 70 . 
Schwefelkohlenstoff, der das Fett gelöst enthielt, beim Schütteln mit Alkohol den Farbstoff an diesen nicht abgab.

Sehr umständlich sind die Verfahren von Stebbins ${ }^{1}$ ) und Leeds ${ }^{2}$ ), welche beide größere Mengen Fett, etwa 50-100 g, verwenden. Ersterer schüttelt das Fett mit Walkererde und extrahiert dann die mit Benzol vom Fett befreite Erde mit $94 \%$-igem Alkohol; letzterer löst das Fett in Petroläther, läßot bei sehr niedriger Temperatur 12-15 Stunden stehen und schüttelt mit ${ }^{1 / 10}$ N.Alkalilauge aus, wodurch der Farbstoff dem Petroläther entzogen werden soll.

Auch nach diesen Methoden gelang es uns nicht, absolut sicher die Gegeuwart fremder Farbstoffe nachzuweisen.

Ein sicherer Nachweis kann jedoch nach der von uns ermittelten Methode geführt werden. Man verfährt wie folgt:

$10 \mathrm{cem}$ geschmolzenes Fett werden in einem kleinen Schütteltrichter, wie ein solcher zum Nachweis von Sesamöl in Margarine gebraucht wird, in $10 \mathrm{ccm}$ Petroläther gelöst; die Lösung wird alsdann nach Zusatz von $15 \mathrm{ccm}$ Eisessig kräftig durchgeschättelt. Ein Farbstoffzusatz ist an der Gelb- oder Rosafärbung des sich als untere Schicht absetzenden Eisessigs erkennbar. Bei nur geringer Farbstoffanwesenheit empfiehlt es sich, die Eisessigfarbstofflösung in eine Porzellanschale zu bringen und sie auf dem Wasserbade einzuengen. Wir haben die Brauchbarkeit dieses Verfahrens sowohl bei gefärbter Butter und Margarine, als auch bei Fetten (Talg, Oleomargarin, Schmalz), die wir selbst mit den gebräuchlichsten Farbstoffen, wie Orleans, Curcuma, Safran, Anilin- und Alizaringelb, Tropäolin, Pikrinsäure, der Butterfarbe des Handels etc. versetzten, erprobt. Stets ließ sich die Gegenwart des fremden Farbstoffes auf diesem Wege leicht erkennen; einige Farben, wie Alizarin- und Anilingelb, sowie Tropäolin geben dem Eisessig eine Rosafürbung.

1) Journ. Americ. Chem. Soc. 1887, 9, 41.

3) Analyst 1887, 12, 150.

\section{Referate.}

\section{Forense Chemie.}

A. Grigorjew: Über die Zerstörung organischer Substanzen bei gerichtlich-chemischen Analysen. (Vierteljahresschr. gerichtl. Med. u. öff. Sanitätsw. 1905, 29, 74-78.) - Die zerkleinerten, bei $70-80^{\circ}$ getrockneten Eingeweide u. s, w. werden im Mörser zerrieben und mit dem 10-fachen Volumen Schwefelsäure zuerst vorsichtig schwach erwärmt und dann stärker erhitzt. Die völlig verflüssigte Masse läßt man etwas erkalten, setzt $10 \mathrm{ccm}$ rauchende Salpetersäure $(1,52)$ zu und digeriert weiter. Man wiederholt dies noch einmal und wenn das Schäumen nachläBt, gieBt man die Masse in einen langhalsigen $\mathrm{Kjeldahl-Kolben,} \mathrm{der} \mathrm{in} \mathrm{einem}$ Babo'schen Siedeblech steht. Unter lebhaftem Sieden setzt man dann noch einigemal $10 \mathrm{ccm}$ rauchende Salpetersäure zu, bis keine braunen Dämpfe mehr entwickelt werden und die Flüssigkeit hellgelb geworden ist, was bei Anwendung von $10 \mathrm{~g}$ Trockensubstanz in 4-5 Stunden eintritt. Bei Anwesenheit grober Fettmengen geht die Zerstörung langsamer vor sich und es empfiehlt sich dabei, von vornherein der Schwefelsäure $20-30 \%$ Salpetersäure zuzusetzen. Die farblos und klar gewordene 